\title{
STUDI LITERATUR \\ TENTANG FAKTOR-FAKTOR YANG BERPENGARUH DALAM IMPLEMENTASI ENTERPRISE SYSTEM PADA UKM
}

\author{
Sulistyo Heripracoyo \\ Information Systems Department, School of Information Systems, Binus University \\ Jl. K.H. Syahdan No. 9, Palmerah, Jakarta Barat 11480 \\ hpracoyo@binus.edu
}

\begin{abstract}
Small and Medium Enterprises (SMEs) are one of the pillars of Indonesian economy since they contribute to the national Gross Domestic Product in a large number. This study discusses some of the articles to determine the factors that influence the implementation of enterprise applications systems, business intelligence (BI) and cloud computing. SCM, ERP, CRM are applications that provide the benefits of efficiency and effectiveness to the organization that uses and implements them. SCM, ERP, CRM and Business Intelligence needs to be implemented to SMEs in order to improve their performance to compete efficiently and competitively. In addition, SMEs can try cloud computing services by implementing and integrating those applications, although obstacles may be considerable.
\end{abstract}

Keywords: SMEs, SCM, ERP, CRM, business intelligence, cloud computing

\begin{abstract}
ABSTRAK
Usaha Kecil dan Menengah (UKM) merupakan salah satu pilar dari perekonomian Republik Indonesia karena UKM memberikan kontribusi terhadap Pendapatan Domestik Bruto nasional. Penelitian ini membahas beberapa artikel untuk mengetahui faktor-faktor yang berpengaruh dalam implementasi aplikasi-aplikasi enterprise system, business intelligence (BI) dan cloud computing. SCM, ERP, CRM adalah aplikasi yang memberikan manfaat efisiensi dan efektifitas terhadap organisasi yang menggunakan dan mengimplementasikannya. SCM, ERP, CRM dan Business Intelligence perlu diimplementasikan terhadap UKM agar dapat meningkatkan kinerjanya secara efisien dan dapat bersaing secara kompetitif. Selain itu UKM dapat mencoba layanan cloud computing dengan mengimplementasikan dan mengintegrasikan aplikasi-aplikasi tersebut, meskipun tidak tertutup kemungkinan bahwa kendala yang dihadapi cukup besar.
\end{abstract}

Kata kunci: UKM, SCM, ERP, CRM, business intelligence, cloud computing 


\section{PENDAHULUAN}

Keberhasilan dalam menjalankan bisnis tentunya sangat bergantung pada organisasi lain yang terkait dengan rantai pasokan (suply chain) dan pengiriman. Seperti yang sudah diketahui secara umum bahwa suatu organisasi akan memerlukan bahan baku, barang dan sebagainya dari organisasi lain. Organisasi lain sebagai penyedia bahan baku, penyedia barang dan sebagainya bergantung pada pihak lain terhadap transportasi dan sebagainya. Dilihat dari perkembangan rantai pasokan, tahap awal adalah hubungan antara barang (penyimpanan barang/gudang) dan transportasi, selanjutnya dengan adanya jaringan global world wide web (WWW). Maka dari itu, fungsi dari pabrikan (manufaktur), pembelian (procurement) dan pemesanan ditambahkan pada rantai pasokan. Dengan kemajuan teknologi yang berkembang sangat pesat, saat ini telah banyak fungsi lain yang terintegasi di dalam rantai pasokan dari supplier ke customer. (Kumaran dan Ganesan, 2011). Salah satu contohnya adalah dengan kemajuan dalam sistem pertukaran data elektronik (EDI) dan pengambilan keputusan, fungsi pelanggan dan pemasok dapat terintegrasi.

Enterprise Resource Planning (ERP) lebih dikenal sebagai paket perangkat lunak enterprise terintegrasi yang menggunakan perlengkapan modular untuk mendukung berbagai area fungsi kunci dari organisasi. Sistem ERP mengotomasi aktivitas dengan aplikasi perangkat lunak terintegrasi. Fungsi ERP adalah untuk menyediakan aliran informasi di antara seluruh fungsi bisnis di dalam batasan organisasi dan mengatur hubungan dengan stakeholder di luar organisasi.

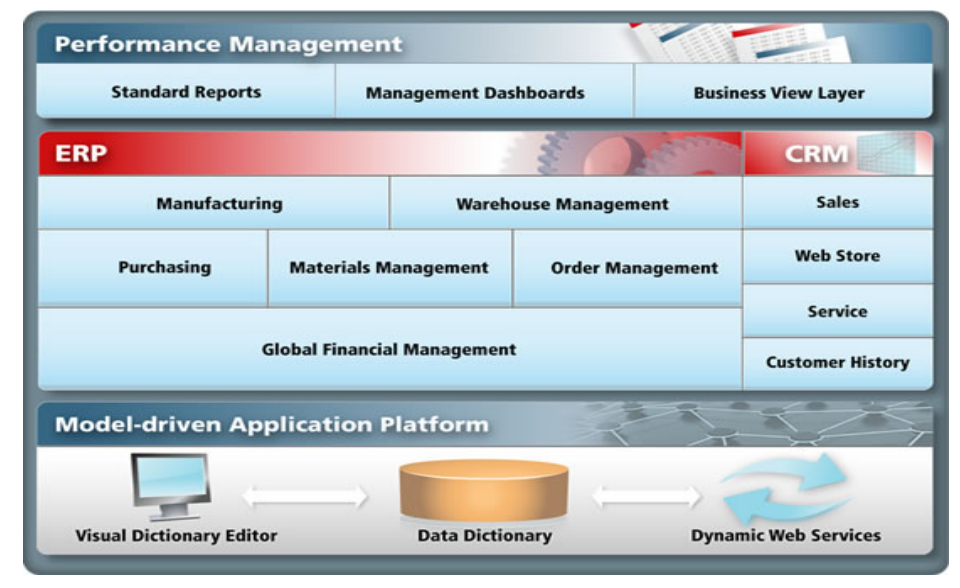

Gambar 1 Arsitektur ERP (Singcat network, n.d.)

Arsitektur software ERP sekarang ini dapat merangkum fungsi-fungsi yang ada dalam suatu bisnis dan mengintegrasikannya dalam satu tempat dari gabungan database (Gambar 1). Misalnya, fungsi dari HRD, Supply Chain Management, Customer Relationship Management, Keuangan, produksi, managemen gudang dan logistik, yang dulunya menggunakan aplikasi/software dan database masing-masing \& terpisah, sekarang disatukan dengan satu payung, yaitu arsitektur ERP. Singcat Network. (n.d.).

CRM (customer relationship management) telah dikenal secara meningkat sebagai suatu strategi bisnis untuk secara etekfif memahami, mengatur, dan mempertahankan hubungan pelanggan dengan teknologi informasi dan komunikasi yang maju. Pengembangan aplikasi manajemen hubungan pelanggan (CRM) yang cepat memperlihatkan pola bahwa beberapa dan banyak usaha kecil dan menengah melihat untuk mengimplementasikan CRM agar dapat bertahan dan bersaing secara global (Fazlzadeh, et al., 2011). Terkait dengan teknologi yang lain, sistem CRM ini dapat diintegrasikan dengan sistem ERP seperti arsitektur dalam Gambar 1 di atas. 
Komputasi sedang berubah dengan model baru, komputasi awan (Cloud computing). Dalam model ini, data dan perhitungan dioperasikan di suatu tempat di"awan", di mana beberapa koleksi dari pusat data (data center) dimiliki dan dikelola oleh pihak ketiga. Cloud computing mengacu pada perangkat keras, perangkat lunak sistem, dan aplikasi yang disampaikan sebagai layanan melalui Internet.

Secara umum, penyedia cloud dibagi ke dalam tiga kategori: (1) infrastruktur sebagai layanan (IaaS) yang menawarkan berbasis web akses ke penyimpanan dan daya komputasi. Konsumen tidak perlu mengelola atau mengendalikan infrastruktur awan yang mendasari tetapi memiliki kontrol atas sistem operasi, penyimpanan, dan aplikasi dikerahkan; (2) platform sebagai layanan (PaaS) yang memberikan pengembang alat untuk membangun dan host aplikasi web; (3) software sebagai service (SaaS) di mana aplikasi dapat diakses dari klien berbagai perangkat melalui antarmuka klien tipis seperti browser web.

Cloud computing yang mengacu pada ketentuan layanan dan pemakaian (konsumsi) melalui Internet, adalah paradigma terbaru yang menjanjikan untuk memberikan komputasi sebagai utilitas (Jiang J, 2010). Cloud computing merupakan langkah penting berikutnya dalam kecenderungan menuju akses murah dan universal terhadap informasi dan sumber daya komputasi canggih yang membantu menutup kesenjangan digital antara yang memiliki-komputer dan yang tidak memiliki (Talukder A.K, 2010). Dalam komputasi awan, pengguna akhir dapat mengakses perangkat lunak yang berfungsi penuh dan layanan online dengan sedikit atau tanpa biaya yang menggunakan komputer atau perangkat komunikasi bergerak murah yang menghubungkan mereka melalui Internet. Penyedia layanan inovatif tidak perlu lagi untuk memiliki dan memelihara infrastruktur pengembangan atau produksi dan secara otomatis dapat meningkatkan operasi produksi mereka untuk memenuhi permintaan jauh lebih mudah dan ekonomis dari kemungkinan dengan pusat-pusat data (data center) internal, hosting tradisional. (Antonopoulos (2010)).

Usaha kecil adalah usaha ekonomi produktif yang berdiri sendiri, yang dilakukan oleh orang perorangan atau badan usaha yang bukan merupakan anak perusahaan atau bukan cabang perusahaan yang dimiliki, dikuasai, atau menjadi bagian baik langsung maupun tidak langsung dari usaha menengah atau usaha besar yang memenuhi kriteria usaha kecil. Usaha menengah adalah usaha ekonomi produktif yang berdiri sendiri, yang dilakukan oleh orang perseorangan atau badan usaha yang bukan merupakan anak perusahaan atau cabang perusahaan yang dimiliki, dikuasai, atau menjadi bagian baik langsung maupun tidak langsung dengan usaha kecil atau usaha besar dengan jumlah kekayaan bersih atau hasil penjualan. Usaha besar adalah usaha ekonomi produktif yang dilakukan oleh badan usaha dengan jumlah kekayaan bersih atau hasil penjualan tahunan lebih besar dari usaha menengah, yang meliputi usaha nasional milik negara atau swasta, usaha patungan,dan usaha asing yang melakukan kegiatan ekonomi di Indonesia. Usaha mikro, kecil dan menengah (UMKM) di Indonesia, seperti juga perusahaan/organisasi besar juga telah menerapkan teknologi untuk proses bisnisnya. Menurut data dari PT Telkom (DBS), saat ini PT Telkom memiliki 155.000 pelanggan dari kalangan UKM, koperasi, dan BPR. PT Telkom dengan divisi DBS tersebut tahun 2011 menargetkan dari penyediaan solusi TI untuk segmen usaha ini bisa memasukkan omset ke perseroan sekitar Rp2,3 triliun. Dibandingkan dengan data dari departemen koperasi (53 Juta), jumlah pelanggan tersebut masih sangat kecil.

\section{METODE}

Penelitian ini dilakukan dengan membandingan beberapa literatur untuk mengetahui beberapa faktor yang berpengaruh terhadap implementasi SCM, ERP, CRM dan adanya dukungan business 
intelligence (BI). Begitu juga dengan studi literatur tentang adopsi komputasi awan (cloud computing) untuk UKM.

\section{Pengaruh E-business dalam SCM pada UKM}

Secara global permintaan pelanggan untuk harga rendah dan kualitas produk dan layanan yang tinggi mendorong retailer, manufacturer dan distributor untuk mencapai efisiensi-biaya yang lebih besar dan menyempurnakan waktu kirim dengan meningkatkan efisiensi rantai pasokan (supply chain) untuk memperoleh manfaat bersaing. Sistem SCM saat ini menghubungkan proses produksi dan rantai pasokan melintasi lokasi yang dibedakan secara geografi. Selain itu e-business memungkinkan supply chain atau manajemen e-supply chain, muncul sebagai operasi dan strategi manufaktur baru melalui penggunaan internet dan teknologi yang lain. Secara global diakui bahwa sekitar $80 \%$ pertumbuhan ekonomi bersal dari sektor UKM. Di negara berkembang lebih dari 70\% dari semua bisnis melalui UKM. Selanjutnya hal tersebut perlu bahwa UKM lintas negara harus mengadopsi strategi untuk mendorong penggunaan e-business dalam perusahaannya yang akan mempunyai dampak pada manajemen rantai pasokan (SCM) (Kumaran dan Ganesan, 2011).

Kumaran dan Ganesan (2011) menyatakan bahwa e-business adalah teknologi yang kuat untuk komunikasi pada antarmuka pembeli-pemasok. Telah diamati dari literatur bahwa pengaruh $e$ business dalam rantai pasokan mengarah ke kemitraan pembeli pemasok dan koordinasi yang lebih baik dan memastikan keunggulan kompetitif. E-business dalam manajemen rantai pasokan UKM meningkatkan kinerjanya dengan meningkatkan kecepatan, pengambilan keputusan yang akurat dan cerdas. Hal ini juga mengarah untuk membentuk strategi untuk keputusan pembelian, tanggung jawab portofolio, perkiraan permintaan pelanggan dan penurunan lead time. Jelaslah bahwa kelangsungan hidup UKM tergantung pada kemampuan untuk mengembangkan sistem pengendalian internal yang diselaraskan dengan berbagai kebutuhan pelanggan mereka dan rantai pasokan. UKM harus mengembangkan diri untuk menggunakan berbagai jenis sistem ERP komersial. Dengan memiliki SCM lebih baik UKM bisa menghemat hingga $20 \%$ dari biaya pengadaan.

Dalam penelitiannya, Power (2008) menyimpulkan bahwa adopsi SCM yang memungkinkan teknologi lebih disukai oleh perusahaan besar, yang pada dasarnya teknologi berdasarkan internet lebih menarik perusahaan besar tersebut, tetapi secara paradoks mungkin akan membuat stres organisasi yang cukup besar (tekanan untuk perubahan). Implikasi bagi perusahaan-perusahaan besar adalah bahwa meskipun manfaat mungkin lebih mudah terlihat, adopsi yang luas bisa dibatasi oleh tingkat dan intensitas dari "diskontinuitas organisasi" yang dialami. Untuk perusahaan menengah tingkatnya lebih rendah terhadap penerapan kedua teknologi, sedangkan untuk perusahaan kecil belum terlihat adanya kesadaran tentang manfaat, atau bahkan mungkin tentang relevansi teknologi ini untuk mereka.

\section{Enterprise Resource Planning (ERP)}

Mukwasi dan Seymour (2012) dalam literaturnya menjelaskan tentang manfaat potensial ERP untuk UKM, yaitu: (1) manfaat operasional; (2) manfaat manajerial; (3) manfaat strategis; (4) manfaat infrastruktur TI; (5) manfaat organisasi. Manfaat operasional meliputi memberikan visibilitas data di seluruh organisasi; memungkinkan otomatisasi proses bisnis; standarisasi proses bisnis; memperbaiki pencarian informasi (pelaporan) dan meningkatkan pemantauan proses dan sebagainya. Manfaat manajerial mengadopsi sistem ERP untuk organisasi, yaitu sistem ERP mendukung pembuatan keputusan yang mudah dan proses perencanaan; mengarah pada perbaikan pengelolaan sumber daya, dan mengarah pada peningkatan kinerja. Untuk manfaat strategis, penerapan sistem ERP mendorong pertumbuhan bisnis dan aliansi; memungkinkan untuk pengembangan hubungan eksternal (dengan pelanggan, pemasok dan klien); mempromosikan inovasi bisnis melalui diferensiasi produk dan mengarah ke kualitas informasi yang ditingkatkan. Manfaat infrastruktur TI berarti bahwa jika 
berhasil, penerapan sistem ERP dilakukan mengarah ke pengurangan biaya Teknologi Informasi (IT); meningkatkan infrastruktur TI, mengembangkan fleksibilitas bisnis untuk perubahan yang ada dan mendatang; memungkinkan penggantian penuaan terhadap infrastruktur TI atau teknologi; mengarah pada peningkatan kapasitas infrastruktur TI; mengembangkan fleksibilitas bisnis untuk perubahan yang ada dan mendatang dan meningkatkan standardisasi teknologi yang digunakan. Manfaat secara organisasi, pelaksanaan sistem ERP mempromosikan perubahan organisasi; meningkatkan pembelajaran bisnis; memberdayakan karyawan dan mereka memungkinkan pembangunan visi bersama dalam sebuah organisasi.

Mukwasi dan Seymour (2012) menyimpulkan bahwa dalam penelitian telah mengintegrasikan pertimbangan kasus bisnis yang berbeda di mana UKM dapat digunakan untuk mengembangkan kasus bisnis yang realistis. Potensi manfaat, risiko dan elemen biaya yang terkait dengan penerapan sistem ERP telah dibuat tersedia untuk UKM dan dirangkum dalam kerangka kerja. Hasil temuan mengatasi kekhawatiran perusahaan di mana kasus bisnis (BC) tidak benar-benar membantu mereka untuk mengenali dan mengelola manfaat yang berbeda selama proses adopsi ERP (Shanks dkk., 2003). Temuan dapat memberikan solusi untuk masalah implementasi-awal terkait dengan membangun kasus bisnis yang realistis dan dapat membantu investor UKM dengan pengambilan keputusan sebelum berinvestasi dalam sistem ERP. Informasi yang UKM dapatkan dari vendor ERP tidak selalu eksplisit dalam membawa keluar kasus-kasus terburuk dari adopsi sistem ERP oleh karena itu kerangka yang diusulkan akan membuat mengerti dalam proses mengadopsi sistem ERP. Agaknya, mereka akan membuat keputusan yang lebih tepat dan kuat.

Abdelghaffar (2012) dalam penelitiannya membagi faktor yang mempengaruhi dampak keberhasilan implementasi ERP dalam perusahaan besar menjadi dua, yaitu faktor yang didasarkan pada kategori level nasional dan level organisasional. Semua manager di negara berkembang, di mana infrastruktur IT (ICT) pada level nasional merupakan hal penting untuk dipertimbangkan oleh perusahaan sebelum implementasi setiap sistem informasi. Faktor lainnya adalah Lokasi ekonomi dan pertumbuhan ekonomi , lingkungan regional dan peraturan pemerintah. Sedangkan untuk level organisasional faktor yang mempengaruhi keberhasilan implementasi ERP adalah IT maturity (tersedia infrastruktur TI), computer culture (sudah mengimplementasikan TI), ukuran bisnis (besarnya ukuran bisnis).

\section{Customer Relationship Managemeng (CRM)}

Fazlzadeh, et al. (2011), menjelaskan faktor-faktor utama yang penting dalam implementasi CRM yaitu: (1) infrastruktur komunikasi-distribusi (keefektifan saluran distribusi, database, data mining, otomasi sales force, rancangan CRM berbasis website); (2) bisnis dinamis (business image, kualitas aktivitas bisnis, tujuan untuk mendapatkan keunggulan kompetitif); (3) hubungan pelanggan (pelatihan dan perilaku, hubungan pelanggan Jangka panjang, memperkenalkan pelanggan dengan memanfaatkan produk dan jasa, ide mempertahankan pelanggan); (4) kualitas dan inovasi (globalisasi dan kemajuan terbaru dalam teknologi informasi, ide untuk mendapatkan pelanggan baru, produk dan kualitas layanan). Faktor utama yang dihadapi oleh UKM adalah komunikasi yang kurang dan dukungan anggaran/dana yang kurang. Oleh karena itu perlu penyempurnaan yang perlu diambil oleh UKM yaitu teknologi informasi dan komunikasi, partisipasi pelanggan, bisnis yang dinamis secara internal, kemudahan penggunaan, kualitas dan inovasi, fleksibilitas dan keamanan.

\section{Business Intelligence}

Sadok dan Lesca (2009), dalam literaturnya menjelaskan di pasar yang sangat kompetitif, dan karena evolusi yang kompleks dan percepatan konteks ekonomi dan teknologi, perusahaan perlu fokus pada pengelolaan secara proaktif proses bisnis intelligence mereka untuk menjamin kelangsungan hidup dan untuk merespon secara efisien untuk perubahan lingkungan yang berubah-ubah. BI adalah 
proses mengumpulkan dan menginterpretasikan informasi yang bersangkutan mengenai lingkungan eksternal, pengetahuan yang dapat membantu keputusan strategis, dan menghasilkan atau mempertahankan keunggulan kompetitif jangka panjang.

Menururt Bara, et al. (2009), sistem BI memiliki potensi untuk memaksimalkan penggunaan informasi dengan mengimprovisasi kemampuan perusahaan untuk struktur volume besar informasi dan membuatnya dapat diakses, sehingga menciptakan manfaat kompetitif : "bersaing pada analisis". BI menggunakan sejumlah besar data yang dikumpulkan selama proses operasional sehari-hari, dan mengubah data menjadi informasi dan pengetahuan untuk menghindari anggapan dan ketidaktahuan dari perusahaan. Karakteristik utama dari BI adalah: kemampuan memberikan informasi yang mewakili kepada manajemen tingkat tinggi, untuk mendukung kegiatan strategis seperti penetapan tujuan, perencanaan dan peramalan, dan kinerja juga pelacakan, untuk mengumpulkan, menganalisis, dan mengintegrasikan data internal dan eksternal ke dalam profil dinamis dari indikator kinerja utama. Berdasarkan kebutuhan informasi setiap eksekutif, BI dapat mengakses kedua data historis dan realtime melalui ad-hoc query. Intinya, manajer di setiap tingkat dapat memiliki pandangan yang disesuaikan yang mengekstrak informasi dari sumber yang berbeda dan merangkum menjadi indikator yang berarti.

\section{Komputasi Awan (Cloud Computing)}

Layanan Cloud saat ini merupakan topik yang paling panas dalam dunia TI, dan hal ini tidak mengejutkan. Keuntungan di sektor ini akan melebihi dari \$150 milyar di tahun 2013. Kenyataannya, estimasi dari Coda Research adalah perusahaan-perusahaan akan berpindah sampai dengan 20 persen dari total pengeluaran IT-nya untuk menempatkan atau berlangganan teknologi layanan di tahun 2015 (Taylor. et al., 2010).

Meskipun layanan awan (cloud) mungkin menjadi bahan pembicaraan di dunia TI, istilah tersebut tidak berarti banyak bagi UKM khusus (smal and medium-sized business). Hanya 20 persen mengaku tahu apa yang arti istilah tersebut, dan hanya tambahan 35 persen mengaku telah mendengar istilah sebelumnya. Tingkat kesadaran adalah langsung berhubungan dengan ukuran perusahaan. Enam puluh lima persen perusahaan Menengah menyadari istilah tersebut, berbeda dengan hanya 30 persen perusahaan Sangat Kecil memiliki apapun pemahaman tentang istilah tersebut. Survei yang telah dilakukan di Amerika menyatakan, UKM sangat puas dengan layanan cloud yang mereka sedang gunakan. Rata-rata, mereka menilai tingkat kepuasannya sebagai 7.8 (dari 10), dengan kurang dari 10 persen responden peringkat kepuasan mereka adalah 5 atau kurang dari itu. Sumber terbesar nilai dari layanan cloud mereka saat ini berasal dari: memaksimalkan investasi, akses ke inovasi, kemampuan untuk fokus pada bisnis dan bukan teknologi, kemudahan penggunaan dan integrasi. Sedangkan dari hasil survei di Jerman, pada tahun yang sama, tingkat kepuasannya sebagai 7.4 (dari 10), sumber terbesar nilai dari layanan cloud mereka saat ini berasal dari: akses ke inovasi, Nilai untuk uang, fokus pada bisnis daripada teknologi, dan kemudahan instalasi atau integrasi (Taylor, et al., 2010). Manfaat potensial untuk bisnis skala kecil dan menengah (UKM) dari komputasi awan, di mana aplikasi atau data dapat diakses di Internet bukan di satu komputer atau jaringan swasta, data telah didokumentasikan dengan baik. Penelitian oleh McKinsey menegaskan bahwa pada tahun 2010, 80\% belanja publik awan (cloud) berasal dari UKM (Muller 2010).

\section{Analisis}

Untuk implementasi SCM, e-business adalah teknologi yang kuat untuk mendukung komunikasi antara pembeli dan pemasok dengan koordinasi yang lebih baik, untuk e-business dalam manajemen (SCM) untuk UKM dapat meningkatkan kecepatan, pengambilan kebutusan yang akurat dan cerdas. Dalam implementasi SCM ini, faktor teknologi sangat berperan. UKM umumnya masih mempunyai kesadaran yang rendah terhadap adopsi teknologi. 
Potensi manfaat, risiko dan elemen biaya yang terkait dengan penerapan sistem ERP telah tersedia untuk UKM. Manfaat secara organisasi, pelaksanaan sistem ERP mempromosikan perubahan organisasi; meningkatkan pembelajaran bisnis; memberdayakan karyawan dan memungkinkan pembangunan visi bersama dalam sebuah organisasi. Kembali seperti disebutkan di atas bahwa faktor teknologi informasi berperan sangat penting dalam implementasi ERP, selain faktor lainnya yaitu Lokasi ekonomi dan pertumbuhan ekonomi , lingkungan regional dan peraturan pemerintah.

Faktor-faktor utama yang penting dalam implementasi CRM di dalam UKM, yaitu: (1) infrastruktur komunikasi-distribusi; (2) bisnis dinamis; (3) hubungan pelanggan; (4) kualitas dan inovasi. Dan perlu peningkatan secara khusus terhadap faktor komunikasi dan dukungan anggaran.

Dengan dukungan BI, UKM perlu untuk mengelola informasi yang dapat digunakan sebagai suatu fungsi strategis karena persaingan bisnis yang begitu kuat. Dengan adanya BI dan informasi yang dikelola dengan baik, UKM dapat dengan cepat mengambil keputusan, baik untuk kebutuhan strategis maupun operasionalnya.

Dari penelitian tentang komputasi awan dapat diambil beberapa hal yaitu, komputasi awan merupakan topik yang paling banyak dibahas oleh kalangan TI, begitu juga adopsinya dapat menurunkan anggaran biasa antara 30-70\%. Dengan optimalisasi IT, UKM dapat merencanakan, menjalankan, mengontrol dan mengevaluasi aktivitas bisnisnya secara akurat dan cepat. Teknologi cloud computing dapat menjadi solusi untuk meningkatkan performa bisnis UKM di masa depan, karena tidak perlu mengeluarkan biaya yang besar dalam investasinya. UKM tidak perlu membeli infrastruktur TI sendiri. Dibandingkan dengan teknologi komputer konvensional (investasi infrastruktur sendiri), penggunaan komputasi awan (cloud computing) diperkirakan dapat menghemat $30 \%$ dibandingkan dengan investasi bisnis tradisional (selain dapat menguranti biaya yang lain, lisensi dan personel TI) dan juga dapat mengurangi 73\% konsumsi listrik, serta memaksimalkan fungsi CPU (central processing unit) dengan peningkatan kapasitas dari 5\% menjadi 60\%. Waktu untuk pemasangan juga diklaim menjadi sangat efisien untuk komputasi awan, dari sebelumnya tiga bulan menjadi satu minggu saja.

\section{PENUTUP}

Usaha kecil dan menengah (UKM) merupakan salah satu pilar dari perekonomian Negara Indonesia yang meliputi $20 \%$ cadangan devisa indonesia, dan memberikan kontribusi terhadap Pendapatan Domestik Bruto nasional sebesar 54\%. Jumlah bisnis UKM yang tumbuh dan berkembang sangat besar tersebut perlu didukung dan dikembangan secara terus menerus di berbagai bidang, seperti produksi dan pengolahan, pemasaran, sumber daya manusia, dan teknologi. UKM dapat didukung dalam bidang teknologi informasi yaitu dengan cara mengintegrasikan seluruh aplikasi SCM, ERP, CRM dan BI. UKM umumnya memiliki anggaran yang kecil jika dibandingkan dengan perusahaan besar, oleh karena itu agar dapat mengimplementasikan dan mengintegrasikan aplikasiaplikasi di atas diperlukan suatu komputasi awan (cloud computing) yang disediakan oleh vendor.

Dengan mengadopsi komputasi awan dan mengintegrasikan aplikasi-aplikasi tersebut, UKM dapat meningkatkan hubungan baik dengan vendor penyedia pasokan bahan dan pelanggan melalui aplikasi SCM, dapat dengan baik mengatur sumber daya yang digunakan melalui aplikasi ERP dan juga pengelolaan data dan informasi yang baik melalui aplikasi BI dan CRM. Namun demikian, pengintegrasian tersebut tidak mudah, banyak faktor yang mempengaruhi dan menghambat implementasi aplikasi-aplikasi tersebut, baik dari infrastruktur, biaya, sumber daya, lingkungan/budaya dan sebagainya. Dengan dukungan vendor yang menyediakan berbagai aplikasi tersebut melalui komputasi awan, UKM dapat mempertimbangkan untuk mengimplementasikan 
aplikasi-aplikasi tersebut sebagai langkah modernisasi dan meningkatkan efisiensi dan kinerjanya untuk tetap dapat bersaing secara kompetitif dan secara global.

\section{DAFTAR PUSTAKA}

Abdelghaffar, Hany (2012). Success Factors for ERP Implementation in Large Organizations: The Case of Egypt. EJISDC, 52(4), 1 - 23.

Antonopoulos, Nick; Gillam, Lee. (2010). Cloud Computing: Principles, Systems and Applications, Computer Communications and Networks. London: Springer-Verlag.

Bara, A., Botha, I., Diaconita, V., Lungu, I., Velicanu, A., Velicanu, M. (2009). A model for business intelligence systems' development. Informatica Economică, 13 (4).

Fazlzadeh, Alireza; Mostafa Moshiri Tabrizi1; Kazem Mahboobi. (2011). Customer relationship management in small-medium enterprises: the case of science and technology parks of Iran. African Journal of Business Management, 5(15), 6160 - 6168.

Kumaran, L.Aravindh; Ganesan, R. (2011), Influence of e-business in SME's supply chain management: a status review. European Journal of Social Sciences, 23 (3).

Mukwasi, Carrington M. dan Seymour, Lisa F. (2012). Enterprise resource planning business case considerations: a review for small and medium-sized enterprises. Journal of Innovation Management in Small \& Medium Enterprises, 2012 (2012).

Muller, S. (2010). The Challenges of Cloud Adoption for SMBs. Diakses dari http://www.idgconnect.com/blog-abstract/468/sven-muller-global-the-challenges-cloudadoption-smbs?region=asia.

Power, Damien (2008). adoption of supply chain management enabling technologies: comparing small, medium and larger organizations. Operations and Supply Chain Management, 1(1), 31 -42 .

Sadok, M.; Lesca, H. (2009). A Business intelligence model for smes based on tacid knowledge. Communications of the IBIMA, 7, $1943-7765$.

Singcat Network. (n.d.). ERP (Enterprise Resource Planning). Diakses dari http://singcat.com/erp.html.

Taylor, S., Young, A., Macaulay, J. (2010). Small Businesses Ride the Cloud: SMB Cloud Watch. Diakses dari http://www.cisco.com/web/about/ac79/docs/pov/SMB_Cloud_Watch_FINAL_FINAL_02181 0 .pdf 